Improved Method for Laser Damage Testing Coated Optics

M. R. Borden, J. A. Folta, C. J. Stolz, J. R. Taylor, J. E. Wolfe, A. J. Griffin, M. D. Thomas

October 28, 2005

Boulder Damage Symposium

Boulder, CO, United States

September 19, 2005 through September 21, 2005 
This document was prepared as an account of work sponsored by an agency of the United States Government. Neither the United States Government nor the University of California nor any of their employees, makes any warranty, express or implied, or assumes any legal liability or responsibility for the accuracy, completeness, or usefulness of any information, apparatus, product, or process disclosed, or represents that its use would not infringe privately owned rights. Reference herein to any specific commercial product, process, or service by trade name, trademark, manufacturer, or otherwise, does not necessarily constitute or imply its endorsement, recommendation, or favoring by the United States Government or the University of California. The views and opinions of authors expressed herein do not necessarily state or reflect those of the United States Government or the University of California, and shall not be used for advertising or product endorsement purposes. 


\title{
Improved Method for Laser Damage Testing Coated Optics
}

\author{
Michael R. Borden*a , James A. Folta ${ }^{\mathrm{a}}$, Christopher J. Stolz \\ John R. Taylor ${ }^{\mathrm{a}}$, Justin E. Wolfe ${ }^{\mathrm{a}}$, Andrew J. Griffin ${ }^{\mathrm{b}}$, Michael D. Thomas ${ }^{\mathrm{b}}$ \\ ${ }^{a}$ University of California, Lawrence Livermore National Laboratory, Livermore, CA 94550; \\ ${ }^{\mathrm{b}}$ Spica Technologies Inc., Hollis, NH 03049
}

\begin{abstract}
The damage test procedure for qualifying a coating run of anti-reflection coated optics consists of scanning a pulsed $1064 \mathrm{~nm}$ laser over a $1 \mathrm{~cm} \times 1 \mathrm{~cm}$ area on a test sample to illuminate approximately 2400 sites. Scans are repeated at 3 $\mathrm{J} / \mathrm{cm}^{2}$ increments until the fluence specification for the optic is reached. In the past, initiation of 1 or more damage sites was classified as a failed coating run, requiring the production optics in the corresponding coating lot be reworked and recoated. Recent laser damage growth tests of 300 repetitive pulses performed on numerous damage sites revealed that all were stable up to $20 \mathrm{~J} / \mathrm{cm}^{2}$. Therefore the acceptance criteria has been modified to allow a moderate number of damage sites, as long as they are smaller than the allowed dig size and are stable (do not grow). Consequently many coating runs that previously would have been rejected are now accepted, resulting in higher yield, lower cost, and improved delivery schedule. The new test also provides assurance that initiated damage sites are stable during long term operation.
\end{abstract}

Keywords: antireflection coating, laser damage, initiation, growth.

\section{INTRODUCTION}

The National Ignition Facility (NIF) project is in the production phase of procuring approximately 25,000 small optics $(<20 \mathrm{~cm})$ that will be used in the main beamlines and diagnostic systems ${ }^{1}$. Of these, roughly 8,000 will be exposed to beam fluences high enough to warrant a laser damage specification for the optical coatings. A laser damage test employing a raster scan of a $1 \mathrm{~mm}\left(1 / \mathrm{e}^{2}\right)$ spot size beam at a wavelength of $1064 \mathrm{~nm}$ was developed to provide the quality assurance that optics from particular coating lots will not damage in use, as well as to qualify coating vendors and perform process control monitoring. This test, which involves illuminating approximately 2400 sites at each fluence level, has been shown to find the damage sites that would initiate at the lowest fluences more readily than alternative damage tests such as ISO 10110-132.

The requirement that a particular coating would "pass" the laser damage test has heretofore been limited to those coatings with no damage sites when tested up to the specification fluence. This requirement has resulted in the rejection of numerous coating runs. Of particular concern was rejection of optic coating runs for which the damage test initiated only a few damage sites, especially when tests on different areas on the same sample provided different results. For example, Figure 1 shows damage test results at 2 locations on the same optic: location A would have failed a specification of $13 \mathrm{~J} / \mathrm{cm}^{2}$ with 2 damage sites, yet location B would have passed. The authors desired a test which would provide more information for the lot acceptance decision, either that the coating run was of insufficient quality or that the run would reliably withstand the required fluence.

In particular, antireflection coatings have been difficult to obtain consistently with no damage sites at the specification fluence. This is believed to be due to absorbing defects at the substrate and coating interface ${ }^{3}$. The production of antireflected coated optics is complicated by the fact that the coating runs on both sides must pass to yield usable optics.

In order to mitigate this concern, a new test protocol has been developed, tested, and implemented into production. The new testing protocol allows up to 10 damage sites providing they are stable (do not grow) upon subsequent exposure to laser fluences up to the specification fluence. The approach of allowing stable damage sites is consistent with the concepts of a functional damage threshold ${ }^{4}$ and conditioning large optic $(>40 \mathrm{~cm})$ mirrors for $\mathrm{NIF}^{5}$. 


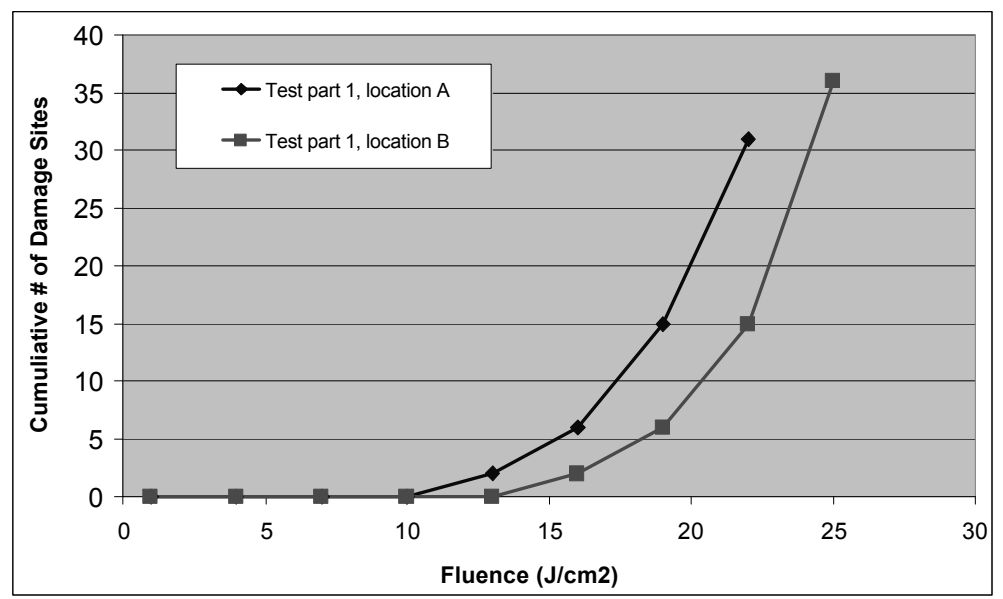

Figure 1. Plot of 2 separate damage test results for different areas tested on the same part. Note the test at location A would result in the coating run failing a damage specification of $13 \mathrm{~J} / \mathrm{cm}^{2}$ since 2 damage sites occurred, yet the test at location B would result in the coating passing the same $13 \mathrm{~J} / \mathrm{cm}^{2}$ specification.

\section{EXPERIMENTAL}

\subsection{Damage Test System}

The NIF Small Optics laser damage test system currently employed at Spica is shown in Figure 2 (A recently qualified NIF small optics laser damage test system developed by Research Electro-Optics is the subject of another paper in these proceedings) ${ }^{6}$ The system employs a Q-switched $1064 \mathrm{~nm} \mathrm{Nd:YAG} \mathrm{laser} \mathrm{with} \mathrm{a} \mathrm{pulsewidth} \mathrm{of} 3.5 \mathrm{~ns}$, and repetition rate of $10 \mathrm{~Hz}$. The $1 / \mathrm{e}^{2}$ spot size is nominally $1 \mathrm{~mm}$.

Damage is detected with an in-situ scatter-based diagnostic. A HeNe laser is co-aligned such that it overlaps the test beam at the test sample surface. The scatter signal is detected with a CCD camera and 40X magnification. The system operator views the scatter signal in real-time on a CRT display. A DVD recorder is used to provide a back-up video for later playback, if necessary.

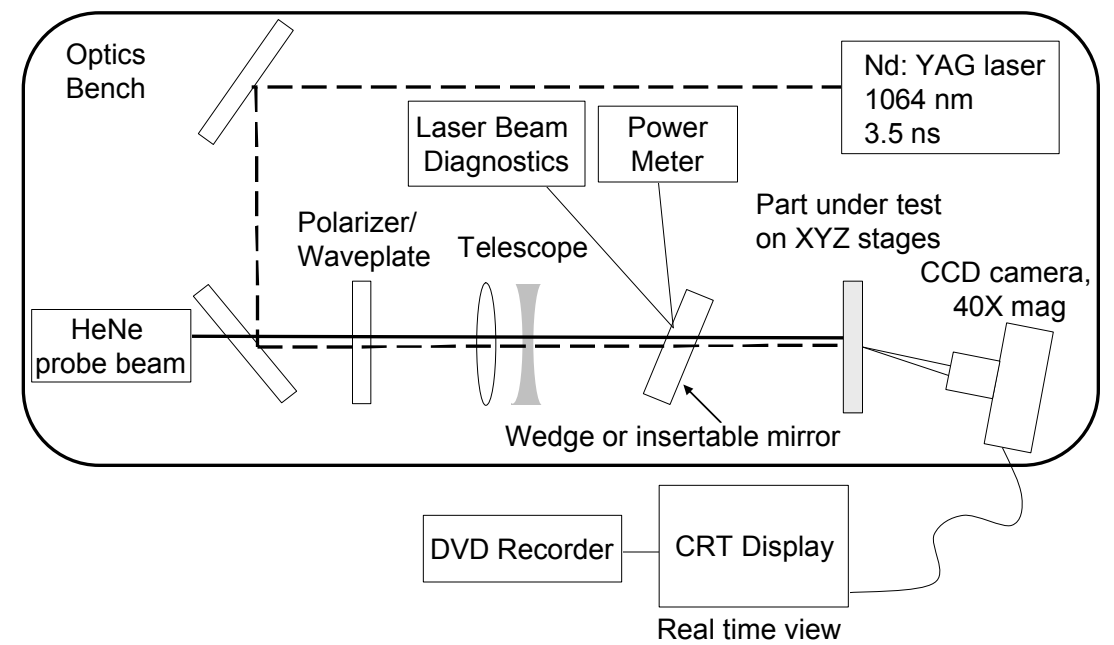

Figure 2. Schematic of the NIF Small Optics laser damage test system in operation at Spica Technologies. 


\subsection{Damage Test Procedure}

The authors believe that damage initiation at isolated defect sites limit the fluence at which an optic can be reliably used. Therefore a large number of test sites are exposed to find isolated defect sites, specifically at the lowest fluence levels at which they would initiate damage. The optic under test is moved with a set of XY stages such that the pulsed laser beam scans a $1 \mathrm{~cm} \times 1 \mathrm{~cm}$ area in a serpentine fashion (see Figure 3). The stage velocities are timed such that there is a beam overlap at $90 \%$ of the peak fluence (see Figure 4). This results in approximately 2400 spots being tested at a fluence at least $90 \%$ of the peak fluence over the entire test area. Mirror and polarizer coatings are tested on the input surface, while anti-reflection coatings are typically tested on the output surface. The typical area tested of $1 \mathrm{~cm}^{2}$ per run represents a small fraction of the area of optics being coated; the ratio of the coated area to the tested area varies from 15:1 for the smallest lots to as high as 2400:1 for larger vacuum windows. Testing a larger fraction of the area is cost prohibitive.

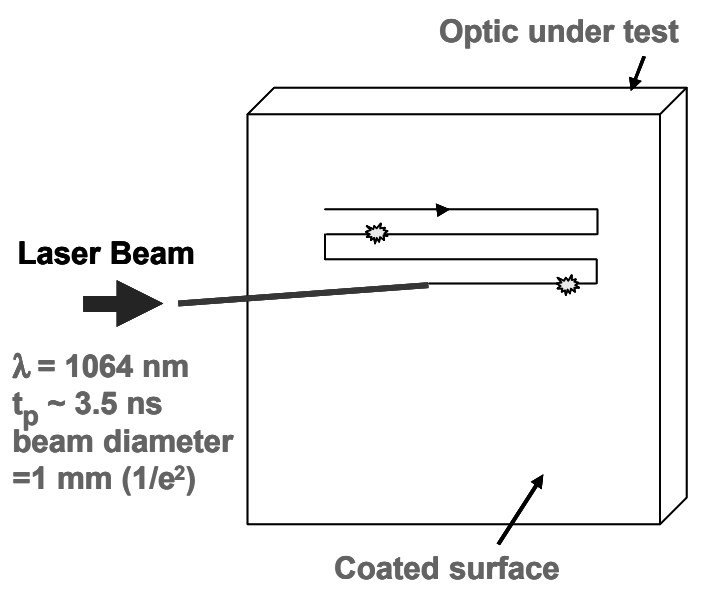

Figure 3. Schematic showing the laser damage test procedure for coated optics.

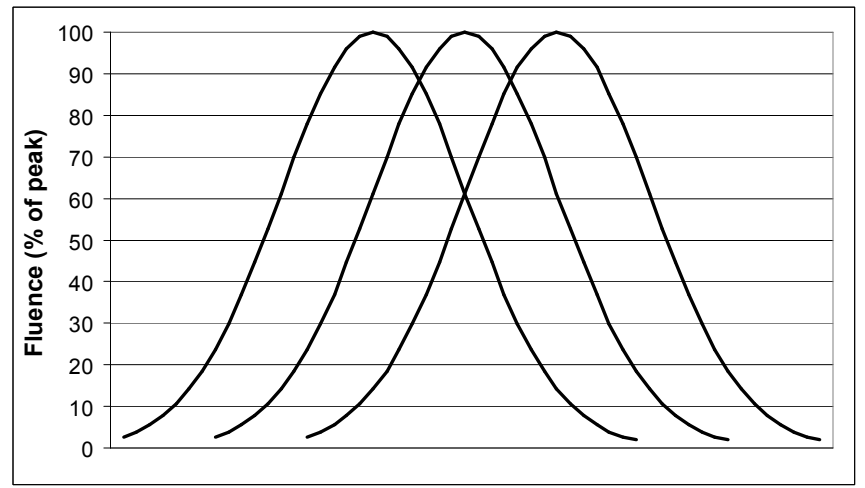

Figure 4. Beam overlap is at the $90 \%$ fluence level.

Each scan is performed at a single fluence. Subsequent scans are increased in $3 \mathrm{~J} / \mathrm{cm}^{2}$ increments. The first scan is performed at a fluence of 1,2 , or $3 \mathrm{~J} / \mathrm{cm}^{2}$ (selected such that a subsequent scan arrives exactly at the specification fluence). The test is continued at least until the specification fluence is reached. 


\subsection{Initial Tests for Damage Site Growth}

An experiment was designed to elucidate the fluence at which damage sites would begin to grow on representative antireflection coated parts. Coated samples were scanned at increasing fluences as described earlier. However, after a damage site was initiated, the scans were stopped. The damage site was inspected with a microscope at 200X magnification to determine the damage site size. The optic was positioned such that the damage site was in the beam, and it was subjected to an additional 300 laser pulses while the scatter signal from the HeNe beam was monitored for any increased scatter level that might indicate an increase in damage site size (damage "growth"). Any change to the site during the first 20 shots was considered cleanup and stabilization of the site, not growth (based on prior experience). Any increase in size occurring after the first 20 shots was considered growth. Following the additional pulses, the damage site size was rechecked with the microscope. If no growth occurred, the fluence was increased by $3 \mathrm{~J} / \mathrm{cm}^{2}$ and the damage site was exposed to an additional 300 shots. This process was continued until growth was deemed to have occurred, or an acceptably high test fluence was reached.

\subsection{Implementing New Damage Test in Production}

Since the new damage test protocol allowed some damage sites, there was some concern about how close the specification fluence was to the region where the damage sites increased rapidly with fluence (see Figure 1 for example, where the number of sites increased rapidly around $20 \mathrm{~J} / \mathrm{cm}^{2}$ ). Given the tolerance on test beam fluence of $15 \%$, a sample that tested with 10 sites on the low side of the fluence tolerance may have many more defect sites at the actual specification fluence. Therefore an additional $3 \mathrm{~J} / \mathrm{cm}^{2}$ scan was added to the damage test fluence requirement. The scans would continue to the specification fluence, and then an additional scan would be performed at $3 \mathrm{~J} / \mathrm{cm}^{2}$ above the specification fluence.

A limit of 10 damage sites was selected based on prior experience with the size of the damage sites compared to the obscuration allowed due to scratches and digs in these optics (the area represented by 10 typical laser damage sites is about $1 / 3^{\text {rd }}$ that of the allowable dig area on a representative NIF small optic). If a total of 10 or fewer damage sites occurs, they would be tested for growth with 300 additional shots at the specification fluence. If no growth occurs on any of the sites, the coating would pass the new acceptance criteria.

\section{RESULTS AND DISCUSSION}

\subsection{Damage Sites Growth Tests}

The result of the tests to determine the fluences at which damage sites would begin to grow for test sample \#1 is shown in Figure 5. In test sample \#1, one site was initiated at a fluence of $7 \mathrm{~J} / \mathrm{cm}^{2}$. Subsequent 300-pulse growth tests were continued until $28 \mathrm{~J} / \mathrm{cm}^{2}$, the fluence at which the coating failed catastrophically. Therefore this site was exposed to at least $25 \mathrm{~J} / \mathrm{cm}^{2}$ without growth. Photomicrographs of a damage site after initiation and after the growth tests are shown in Figure 6. Additional initiation scans were conducted until another damage site occurred at $13 \mathrm{~J} / \mathrm{cm}^{2}$. This site began to grow at a fluence of $25 \mathrm{~J} / \mathrm{cm}^{2}$.

The results of the tests to determine the fluences at which damage sites would begin to grow for test sample \#2 are shown in Figure 7. For test sample \#2, one site was initiated at a fluence of $10 \mathrm{~J} / \mathrm{cm}^{2}$. Subsequent growth tests were continued until $22 \mathrm{~J} / \mathrm{cm}^{2}$, without any evidence of growth. An additional 3 additional damage sites occurred during a subsequent scan at $13 \mathrm{~J} / \mathrm{cm}^{2}$. All 3 sites were exposed to the growth tests up to $22 \mathrm{~J} / \mathrm{cm}^{2}$ without any evidence of growth. 


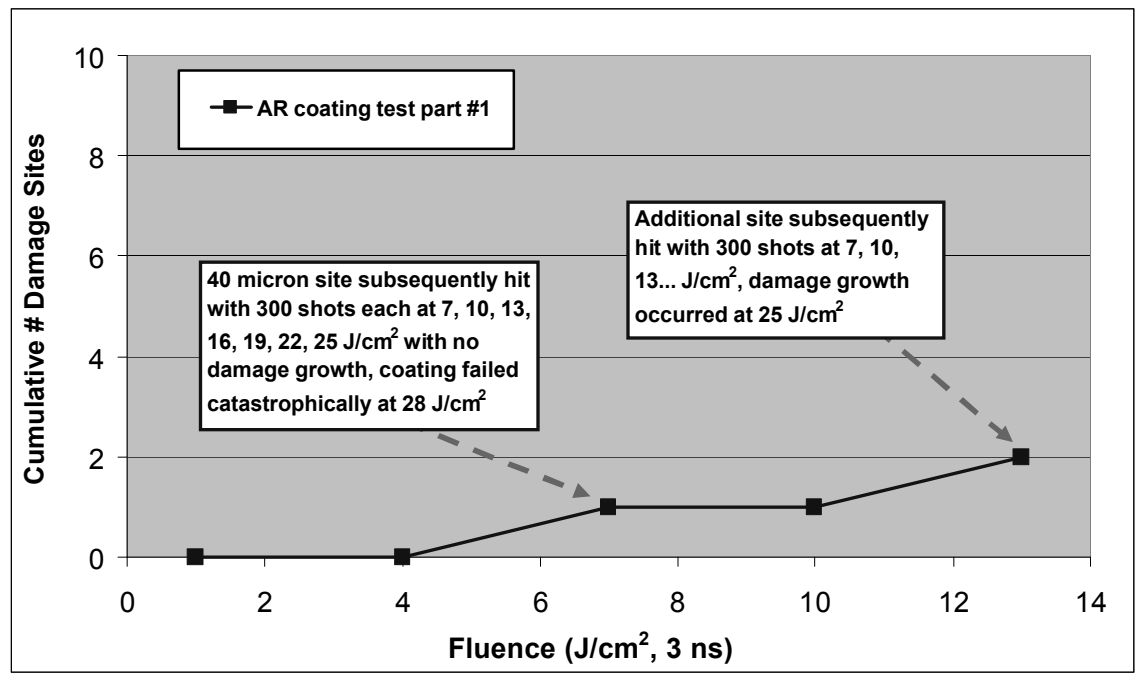

Figure 5. Results of damage site growth tests for anti-reflection coating test sample \#1.

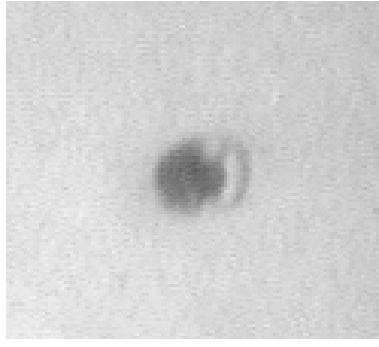

a)

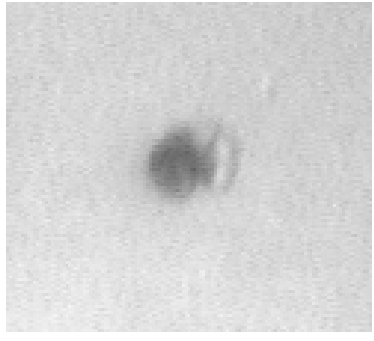

b)

Figure 6. Example of a site tested for growth. Photographs show a nominal 15 micron diameter damage site: a) after initiation; and b) after subsequent exposure to an additional 300 shots at a fluence of $15 \mathrm{~J} / \mathrm{cm}^{2}$ and $3 \mathrm{~ns}$ pulsewidth.

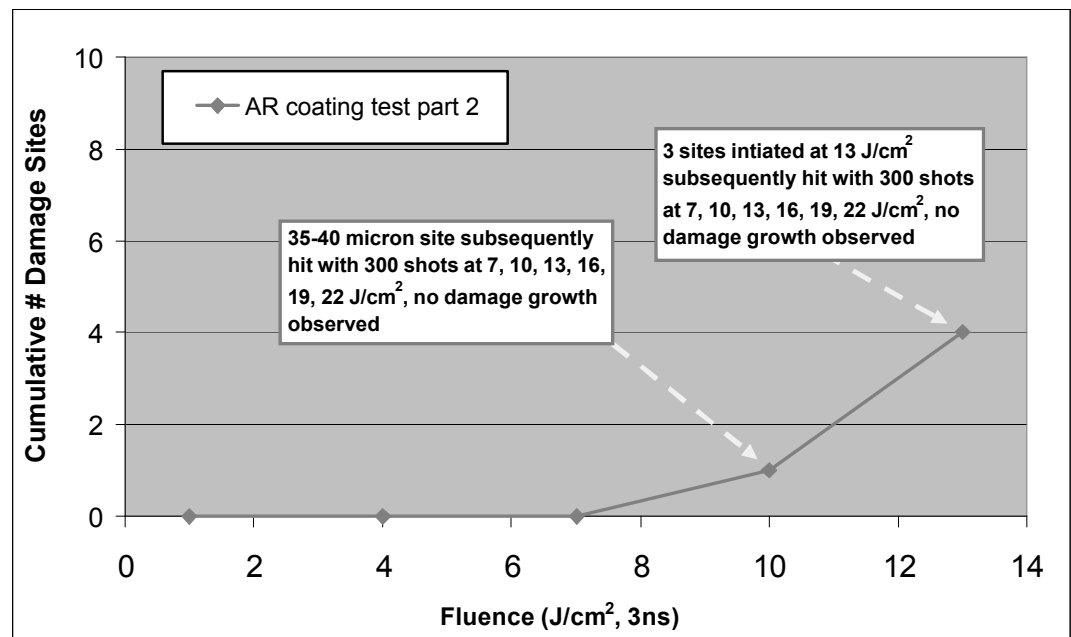

Figure 7. Results of damage site growth tests on anti-reflection coating test sample \#2. 


\subsection{Impact of the New Test on Production Coatings}

Numerous anti-reflection coatings with damage sites have been accepted since the new test protocol was implemented. Some of these are shown in Table 1.

Table 1. Damage test results for production coatings that were accepted with the new test protocol with a maximum of 10 stable damage sites. The damage sites that were tested for growth are shown in the grayed cells for clarity.
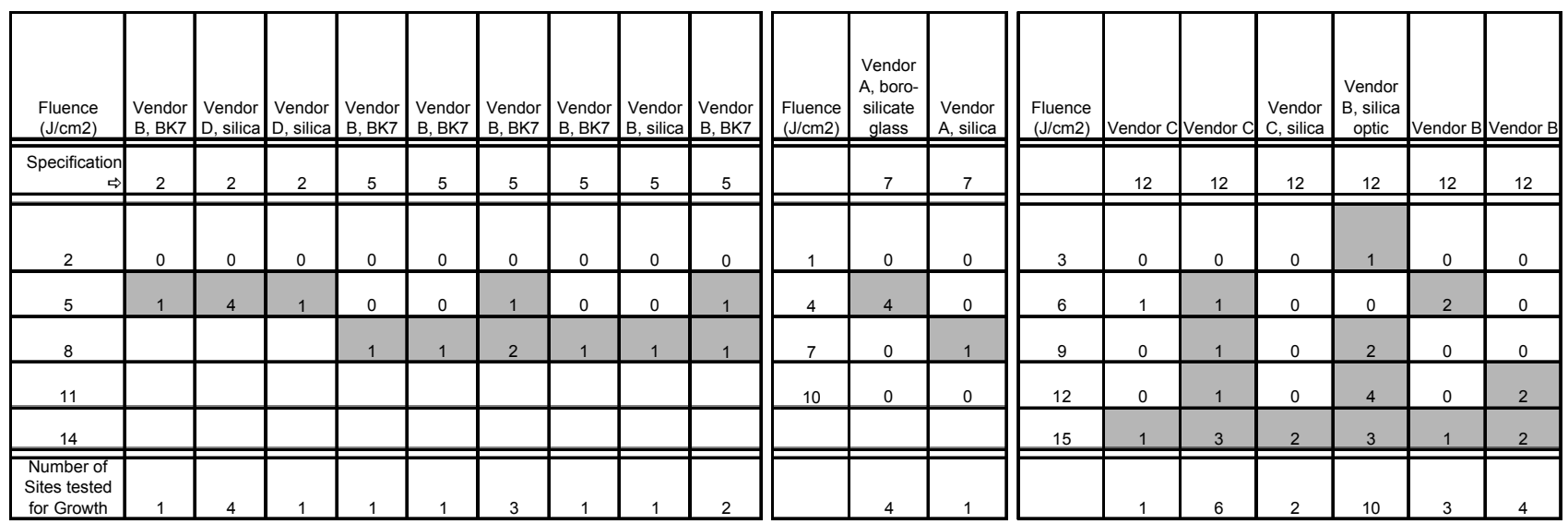

These coating runs represent anti-reflection coatings from 4 different vendors. Both traditional electron beam and ion beam sputtered coatings are represented. The number of damage sites that were tested for growth are summarized at the bottom of each column. Confirmation that damage sites initiated during testing are not susceptible to growth provides increased assurance that the optics are will meet NIF lifetime requirements. The authors are not making a universal claim that all damage sites on AR coatings do not grow at any fluence below $20 \mathrm{~J} / \mathrm{cm}^{2}$; the fluence at which growth occurs depends upon substrate finishing, cleaning and coating procedures, and must therefore be determined for each supplier and manufacturing process.

\subsection{Impact of New Specification on Coating Yield}

Since implementation of the new damage test protocol occurred relatively recently, there is not sufficient data to allow extensive comparison of the yield improvement compared to the original test protocol. Therefore a set of approximately 30 anti-reflection coating damage data curves from one vendor was used to compare which coating runs would have passed with the 2 test procedures. The damage curves, which are plots of the cumulative number of damage sites at the various test fluences, are shown in Figure 8.

It was assumed that none of the damage sites would have exhibited growth up to $15 \mathrm{~J} / \mathrm{cm}^{2}$, which was believed to be a reasonable assumption since none of the sites have grown at these fluences to date. The comparison was performed for 3 typical NIF small optic damage specification fluences: 5,7 , and $12 \mathrm{~J} / \mathrm{cm}^{2}$. 


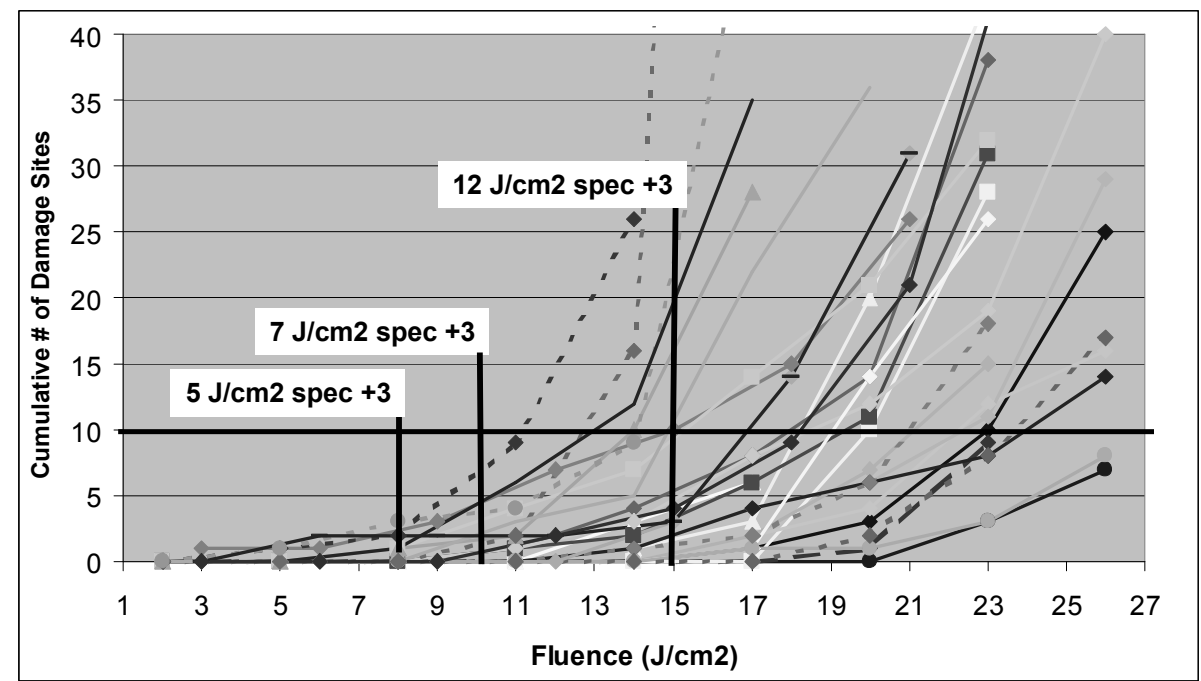

Figure 8. Damage test results for anti-reflection coatings from Vendor A. Three typical specification fluences of 5, 7, and $12 \mathrm{~J} / \mathrm{cm}^{2}$ were used to judge the yield impact of the new damage test protocol.

The results of the comparison are shown in Figure 9.

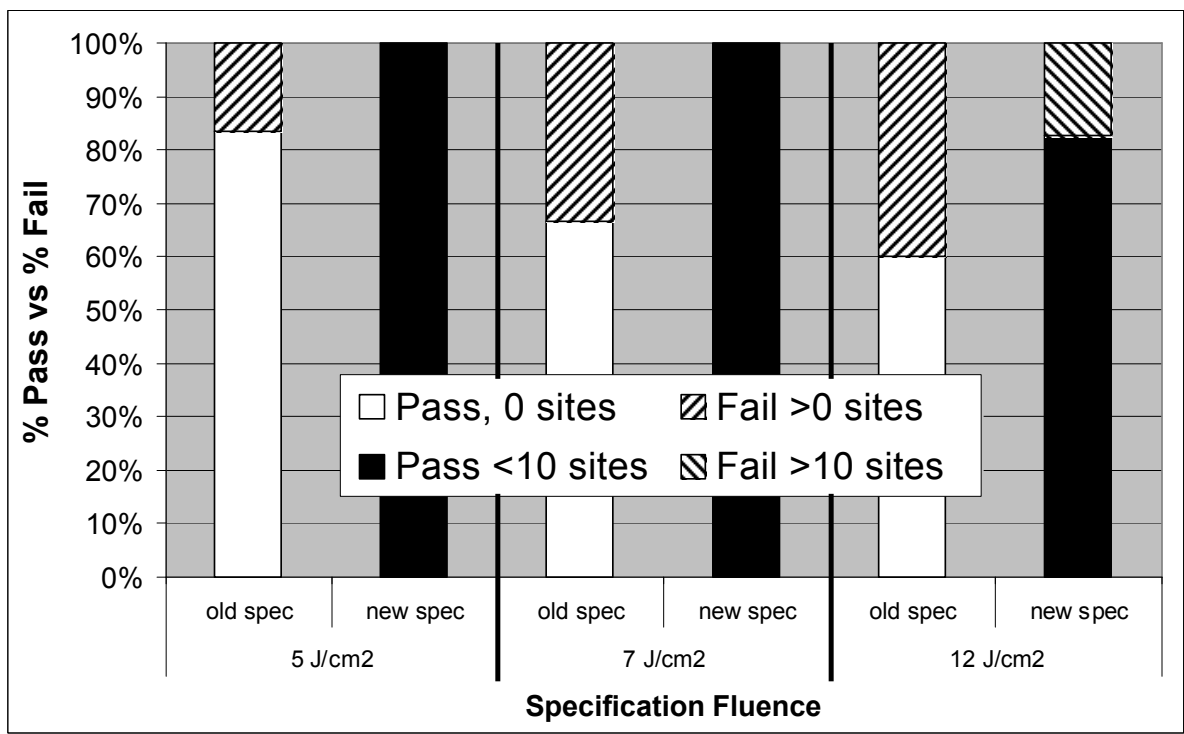

Figure 9. Impact on yield for the damage results of Figure 8 with the new test protocol compared to the original test protocol.

For a $5 \mathrm{~J} / \mathrm{cm}^{2}$ specification fluence, $83 \%$ of the runs would have passed under the original test requirements, compared to $100 \%$ under the new test protocol. This represents an improvement of $20 \%$.

For an $8 \mathrm{~J} / \mathrm{cm}^{2}$ specification fluence, only $66 \%$ of the coating runs would have passed the original test requirement. However $100 \%$ passed under the new protocol, which represents a 50\% improvement in yield.

For the $12 \mathrm{~J} / \mathrm{cm}^{2}$ specification fluence, $60 \%$ of the coating runs would have passed the original test requirement compared to $83 \%$ that would have passed with the new test specification, which represents a yield improvement of approximately $38 \%$. 


\section{CONCLUSIONS}

In conclusion, an improved laser damage test protocol has been developed. The capability to return to damage sites and perform growth tests has been implemented on the NIF damage test system. Growth tests consisting of 300 repeat pulses on initiated damage sites on antireflective coatings have shown that the damage sites do not grow at fluences below 20 microns. The new protocol has been formalized and released as NIF document MEL01-013-0D, Small Optics Laser Damage Test Procedure ${ }^{7}$.

Using the new protocol has resulted in the acceptance of numerous anti-reflection coating runs which would have been rejected under the original qualification criteria. The predicted yield improvement is as high as $50 \%$ depending on the specification fluence. Additionally the new test provides increased assurance that the coated optics are free from damage initiation sites that are susceptible to growth and will therefore meet NIF lifetime requirements.

Future work will involve extending this new test procedure to other types of coatings such as mirrors and polarizers.

\section{ACKNOWLEDGEMENTS}

The authors thank Jeff Atherton, Paul Weber, Chris Haynam, Bob Chow, and Mike Runkel for technical and program support. The authors also thank Andrea Flammini for assistance in preparing this manuscript. This work was performed under the auspices of the U.S. Department of Energy by University of California, Lawrence Livermore National Laboratory under Contract W-705-Eng-48.

\section{REFERENCES}

1. P.J. Wisoff, M.W. Bowers, G.V. Erbert, D.F. Browning, and D.R. Jedlovec, "NIF injection laser system" Proc. SPIE Int. Soc. Opt. Eng. 5341, p 146 (2004).

2. R. Chow, M. Runkel, and J.R. Taylor, "Laser damage testing of small optics for the National Ignition Facility", App. Opt. Vol. 44, No. 17, 3527 (2005)

3. C.K. Carneglia, "Oxide coatings for one micrometer laser fusion systems", Thin Solid Films, 77, 225-238 (1981).

4. J. Taniguchi, N.E. Barron, J. Howe, D.J. Smith, C. Stolz, C. Weinzapfel, and J.Kimmons, "Functional damage thresholds of hafnia/silica coating designs for the NIF laser", SPIE Vol. 4347, p. 109 (2001).

5. C.J. Stolz, L.M. Sheehan, S.M. Miracle, and S. Schwartz, "A study of laser conditioning methods of hafnia silica multilayer mirrors", Proc. SPIE Int. Soc. Opt. Eng. 3578, p. 144 (1998).

6. A.D. Streater and D.C. Ness, "Automated system for production laser damage testing of optics", to be published in these proceedings.

7. J. Wolfe, M. Runkel, J. Folta, M. Borden, C. Stolz, and J.R. Taylor, "Small Optics Laser Damage Test Procedure", Tech. Rep. MEL01-013-0D (Lawrence Livermore National Laboratory, Livermore, CA 2005).

*borden5@1lnl.gov; phone 925-423-9006 